\title{
The Indirect Spaced Repetition Concept
}

\author{
Louis Lafleur \\ Ritsumeikan University
}

\begin{abstract}
The main goal of this research is to systemize, build, and test prototype software to demonstrate Indirect Spaced Repetition (ISR) as a viable concept for Second Language Vocabulary Acquisition (SLVA). ISR is designed around well-founded spaced repetition and SLVA principles. Most importantly, it is based on Nation's (2001) recommendation to consider all three tiers of word knowledge (meaning, form, and function/use) and subsequent 18 aspects of word knowledge for a more balanced approach in teaching and learning vocabulary. ISR prototype software was achieved in the conceptual phase of the research. The resulting prototype flashcard software was given an in-depth trial for a period of 2 weeks by seven university students. Participants were given a post-project survey to evaluate ISR software (ISRS) under four categories: enjoyment, usefulness, usability, and general consideration. Post-test survey findings showed above-average satisfaction and consideration to use such software in the future. However, these findings also revealed that some areas could be further improved, such as addressing some hardware/software issues (e.g., IT infrastructure problematics and lag) and integrating gamification elements (e.g., performance feedback/ reports).
\end{abstract}

Keywords: Vocabulary learning, (Indirect) Spaced Repetition, (Spaced) Interleaving, 18 aspects of word knowledge, Computer Assisted Language Learning (CALL)

\section{Background}

Spaced Repetition is often mistaken as a new concept as the term is often associated with recently published study software and applications. In many cases, these programs fail to give credit to the founders of the spaced repetition system (SRS). First, Hermann Ebbinghaus (1885/1964), a cognitive psychologist, established the spacing effect which accounts for why learners have better memory retention when they engage in spaced learning (multiple but short study sessions) compared to when they engage in massed learning (a single or very few long study sessions). Second, Pimsleur (1967) suggested an exponentially expanded spaced review schedule called graduated interval recall. Finally, Sebastian Leitner (1972) systemized such ideas into a spaced-interval-based box/compartment flashcard study system capable of organizing review cards/items across multiple intervals while allowing the addition of new items into the mix at one's convenience. 


\begin{tabular}{|c|c|c|c|c|c|}
\hline Main Algorithm Types \& Intervals & Initial Study & $\begin{array}{l}\text { Interval } \\
\text { (1) }\end{array}$ & $\begin{array}{l}\text { Interval } \\
\text { (2) }\end{array}$ & $\begin{array}{l}\text { Interval } \\
\text { (3) }\end{array}$ & $\begin{array}{l}\text { Interval } \\
\text { (4) }\end{array}$ \\
\hline Expanded ( $\mathrm{x}$ type) $(\sim 12 \mathrm{~h}$ start $\rightarrow \mathrm{x} 2)$ & $\begin{array}{c}\text { day } 1 \\
\text { (start point) }\end{array}$ & $\begin{array}{l}\text { day } 1 \text { or } 2 \\
\text { ( 12 hours) }\end{array}$ & $\begin{array}{c}\text { day } 3 \\
\text { (1 day) }\end{array}$ & $\begin{array}{c}\text { day } 5 \\
\text { (2 days) }\end{array}$ & $\begin{array}{c}\text { day } 9 \\
\text { (4 days) }\end{array}$ \\
\hline Uniform (same) ( $\rightarrow$ every 2 days) & $\begin{array}{c}\text { day } 1 \\
\text { (start point) }\end{array}$ & $\begin{array}{l}\text { day } 3 \\
\text { ( } 2 \text { days) }\end{array}$ & $\begin{array}{c}\text { day } 5 \\
\text { (2 days) }\end{array}$ & $\begin{array}{c}\text { day } 7 \\
\text { (2 days) }\end{array}$ & $\begin{array}{c}\text { day } 9 \\
\text { (2 days) }\end{array}$ \\
\hline Massed learning or (cramming) & \multicolumn{5}{|c|}{$\begin{array}{l}\text { (Total study time compressed into a single session) } \\
\text { E.g., If a study session lasts } 5 \text { minutes: } \\
5 \text { consecutive sessions } \times 5=25 \text { minutes total. }\end{array}$} \\
\hline
\end{tabular}

Figure 1. Typical comparative example of expanded, uniform, and massed algorithms.

Note: Some studies do not utilize intervals but "distractors or fillers" (unrelated items/cards to create pauses within a study session). These essentially divide up a single study session into multiple segments. These segments can be arranged (via careful distractor/filler placement) into uniform or expanded spaced patterns.

Although digitized in recent years, the concept remains largely the same. The learner is presented with a question or a prompt first (traditionally, flashcard side A) for which they must try to recall or guess an appropriate answer before confirming it (traditionally, flashcard side B). If the learner's recall is successful, then that item's study/review interval spacing/length will be increased. After a number of consecutive successful recalls/reviews, the spacing of reviews will move from shorter (e.g., daily) to longer ( $\rightarrow$ weekly, etc.). However, if one's recall fails, this would signify the need for a shorter study/review interval, and therefore, the interval should be reduced considerably (back to the previous or first interval, e.g., daily) before being increased again through successful recall.

In terms of study efficiency, there is an agreement that massed learning (or cramming) is not as efficient as spaced learning. However, there are two different schools of thought about how to spread out study intervals within spaced learning, expanded or uniform (see Figure 1).

- In most comparative studies, uniform interval lengths are longer than expanded intervals at first.

- A good research practice is to have an equivalent number of intervals and total period for fair comparison.

A number of studies found no statistical difference in efficiency between uniform and expanded intervals when tested shortly after their set study periods (Balota, Ducheck, \& Logan, 2007; Carpenter \& DeLosh, 2005; Landauer \& Bjork, 1978). However, longer delayed studies such as Schuetze and Weimer-Stuckmann $(2010,2011)$ showed that the uniform group outperformed the expanded group at $83 \%$ retention versus $59 \%$ on a 9 -month post-test.

The decision to implement expanded interval spacing, thus far, for Indirect Spaced Repetition Software (ISRS) was counter-intuitive, as some efficiency is sacrificed in longer-term recall as Schuetze and Weimer-Stuckmann $(2010,2011)$ 


\begin{tabular}{|c|c|c|c|c|c|c|}
\hline Factor of 2 (5 Intervals) & Initial Study & $\begin{array}{l}\text { Interval } \\
\text { (1) }\end{array}$ & $\begin{array}{l}\text { Interval } \\
\text { (2) }\end{array}$ & $\begin{array}{l}\text { Interval } \\
\text { (3) }\end{array}$ & $\begin{array}{l}\text { Interval } \\
\text { (4) }\end{array}$ & $\begin{array}{l}\text { Interval } \\
\text { (5) }\end{array}$ \\
\hline $\begin{array}{c}\text { Expanded (+ type) } \\
\text { (previous\# } \rightarrow+2 \text { days) }\end{array}$ & $\begin{array}{c}\text { day } 1 \\
\text { (start point) }\end{array}$ & $\begin{array}{c}\text { day } 3 \\
\text { (2 days) }\end{array}$ & $\begin{array}{c}\text { day } 7 \\
\text { (4 days) }\end{array}$ & $\begin{array}{l}\text { day } 13 \\
\text { (6 days) }\end{array}$ & $\begin{array}{l}\text { day } 21 \\
\text { (8 days) }\end{array}$ & $\begin{array}{c}\text { day } 31 \\
\text { (10 days) }\end{array}$ \\
\hline Expanded (x type) $(\rightarrow \times 2)$ & $\begin{array}{c}\text { day } 1 \\
\text { (start point) }\end{array}$ & $\begin{array}{l}\text { day } 1 \\
\text { (later) }\end{array}$ & $\begin{array}{c}\text { day } 3 \\
\text { (2 days) }\end{array}$ & $\begin{array}{c}\text { day } 7 \\
\text { (4 days) }\end{array}$ & $\begin{array}{l}\text { day } 15 \\
\text { (8 days) }\end{array}$ & $\begin{array}{c}\text { day } 31 \\
\text { (16 days) }\end{array}$ \\
\hline $\begin{array}{l}\text { Expanded (ab type) } \\
\left.\text { (E.g., } \rightarrow \sim 19 \mathrm{sec}^{(\#)}\right)^{*}\end{array}$ & $\begin{array}{c}\text { day } 1 \\
\text { (start point) }\end{array}$ & $\begin{array}{c}\text { day } 1 \\
\text { (19 seconds) }\end{array}$ & $\begin{array}{c}\text { day } 1 \\
\text { (6 minutes) }\end{array}$ & $\begin{array}{c}\text { day } 1 \\
\text { ( } 2 \text { hours) }\end{array}$ & $\begin{array}{c}\text { day } 3 \\
\text { (11/2 days) }\end{array}$ & $\begin{array}{c}\sim \text { day } 31 \\
\left(\sim 281 \frac{1}{2} \text { days }\right)\end{array}$ \\
\hline
\end{tabular}

Figure 2. Schedule example for comparison between $\left(+, \times\right.$, and $\left.a^{b}\right)$ expanded algorithms. *The more precise number here was 18.97 seconds.

\# = the interval number and exponent variable in the calculation (e.g., (3rd interval) $19^{3}=19$ seconds $\times 19$ seconds $\times 19$ seconds ) Total $=2$ hours (approx)

have shown. However, expanded spacing is more practical in handling multiple study items/flashcards (e.g., 100 at a time and more) as review cards can be pushed further back more aggressively in later intervals ( $\rightarrow$ monthly, etc.). This aids to alleviate some of the review burden, which permits new cards to be introduced into the study mix more easily.

It is often overlooked that there are actually three types of "Expanded" spacing:,$+ \mathrm{x}$, and $\mathrm{a}^{\mathrm{b}}$ (see Figure 2). What could be perhaps more interesting would be to compare these three types of expanded spacing among themselves in future research.

Beyond scheduling, another important area to address is the profoundness of vocabulary study, a concept known as vocabulary breadth and depth.

On one hand, some SRSs place more importance on breadth (maximizing the number of words encountered) and less on study depth (aspects/levels of word knowledge). A typical example would be the unilateral use of a quick receptive knowledge recall exercise (side $\mathrm{A}=\mathrm{L} 2$ word, and side $\mathrm{B}=$ corresponding L1 word).

On the other hand, some SRSs place more importance on depth, and thus less on breadth. In addition to L1/L2 words, other elements such as L1/L2 definitions, L1/L2 example sentences, audio, images/video may be included. These additional elements can enable a wider range of study, such as focus on forms, four language skills, both receptive and productive knowledge, and different task flows (L1 to L2, L2 to L1, and L2 to L2). One of the drawbacks of creating multiple tasks as additional items/flashcards is the creation of indirect overlap, where some of the prompts or affiliated sound/visuals of a flashcard may comprise the answer/recall elements of a different flashcard. This indeed upsets the desired cool-down period as it constitutes unscheduled review in between set intervals.

ISRS avoids such overlap by not adding extra tasks as additional items/flashcards but cycling between tasks according to the reached interval. This is similar to the concept of interleaving (the consecutive practice of multiple skills or concepts); however, in this case, the interleaved tasks are spaced across increasingly expanding intervals, interval-spaced interleaving (see Figures 3 and 4). ISRS's interleaved tasks are based on three tiers of word knowledge: meaning, form, and function/use (Nation, 2001). ISRS's sequencing is based on the work of Schmitt 


\section{@creative 4.0}

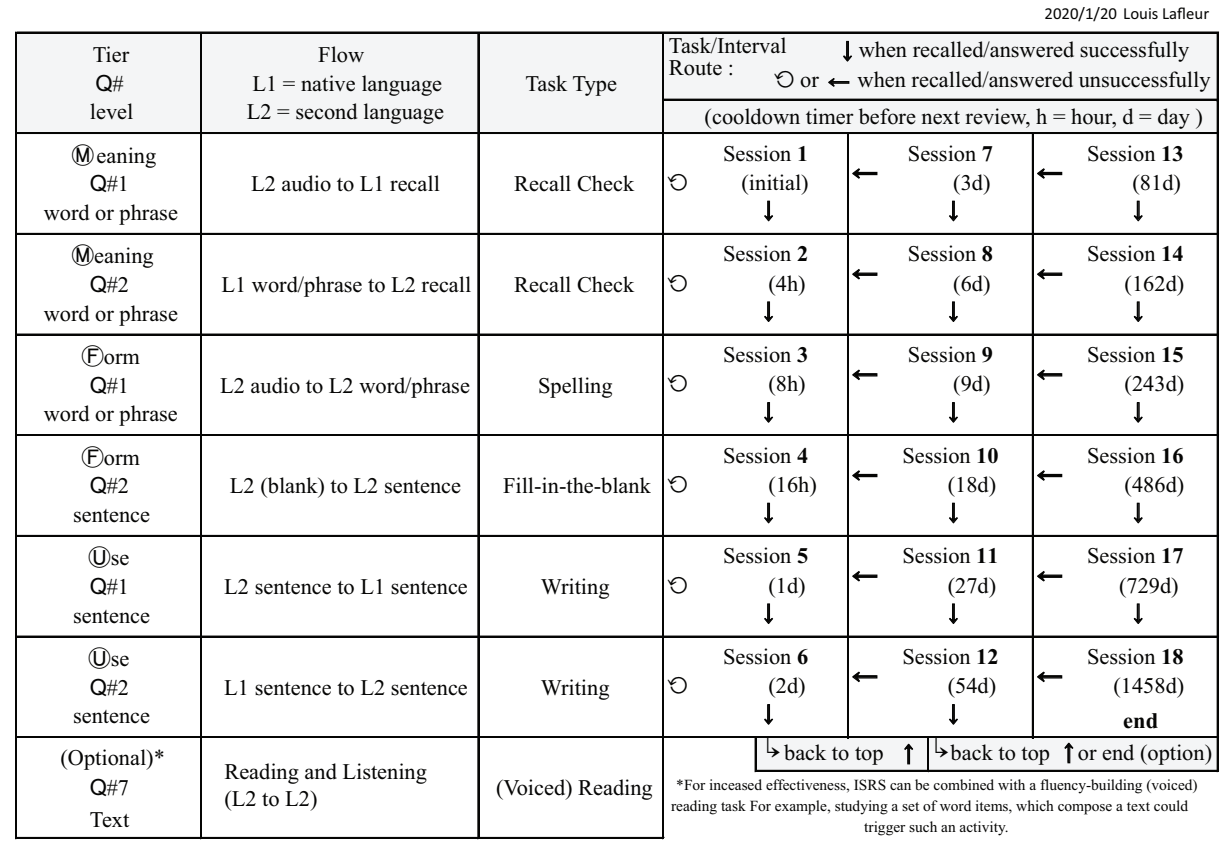

Figure 3. Spaced-Interleaved Task Examples and Interval Breakdown for Indirect Spaced Repetition Software/System (ISRS).

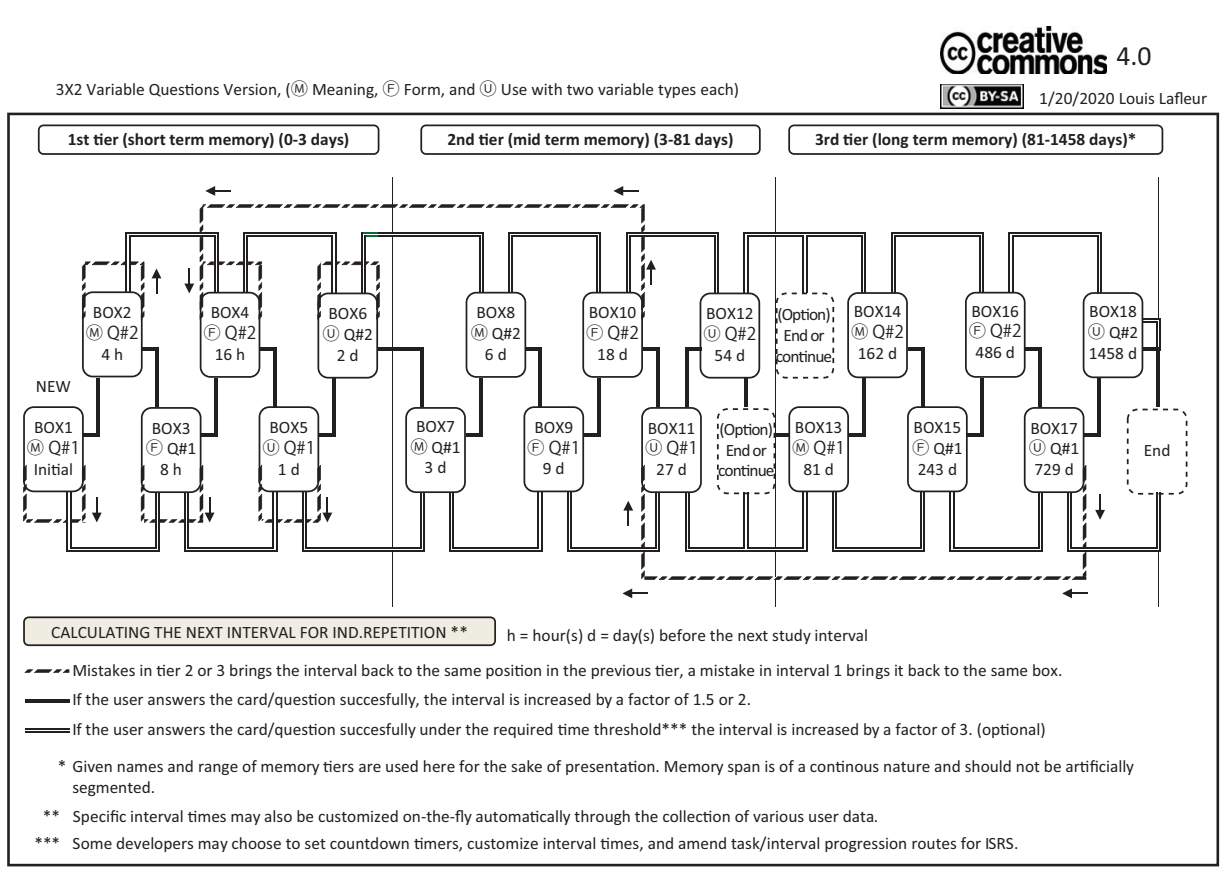

Figure 4. Indirect Spaced Repetition System/Software (ISRS). 
(2008) who implied that focusing on the meaning-form link at first and later enhancing context(use) may prove to be effective.

The following questions guided the ISRS testing:

1. Do the participants find the software useful for JHS (junior high school) students? (Usefulness assessment)

2. Do the participants find the software easy to use for JHS students? (Usability assessment)

3. Do the participants find the software enjoyable for JHS students? (Enjoyment assessment)

4. Do the participants think JHS teachers would like to integrate the software in their classes or in parallel to their classes (homework)? (Consideration assessment)

\section{Methodology}

The participants in this study were five undergraduate students of English education, one undergraduate student of elementary school education and one graduate student of psychology. Two of the participants were female, and the other five were male. Most had teaching experience through working at cram schools and most had undergone 4 weeks of teacher training in a public junior high school. They all completed pre-project and post-project surveys that collected quantitative data (Likert-scale, 1 = Strongly Disagree $\sim 5=$ Strongly Agree) and qualitative data (comments) about the participants' perspectives of e-learning and the ISRS prototype software.

\section{Results and Discussion}

The pre-project survey revealed that four participants had prior experience using SRS software. Although the majority agreed that e-learning can make study more effective $(M=3.71$, standard deviation $[S D]=0.76)$, the reality was that they did not implement e-learning in their own study of English to the level of their beliefs $(M=2.86, S D=1.21)$ (Lafleur, 2015). Neither apathy nor enthusiasm regarding e-learning or SRS could be ascertained.

Regarding the interval scheduling and task interleaving of ISRS, participants were quite content with the prototype software and a good number of participants

\begin{tabular}{|c|c|c|}
\hline Perceptions (5 point Likert-scale, 5 = strongly agree) and Comments (P\# = Participant \#) & Mean & $S D$ \\
\hline (Consideration) I think that teachers would like to incorporate such software in their class. & 3.86 & 1.21 \\
\hline \multicolumn{3}{|c|}{$\begin{array}{l}\text { "The all-surrounding Internet equipped environment required by the software is probably the biggest hurdle facing } \\
\text { current classroom integration." (P3) }\end{array}$} \\
\hline \multicolumn{3}{|l|}{ "One remaining problem is whether students have computers or not to enable review at home." (P5) } \\
\hline \multicolumn{3}{|c|}{$\begin{array}{l}\text { "I think that with the cooperation of teachers this tool/software's effectiveness can be even greater for students. } \\
\text { I want to incorporate such a system as part of the routine of my future classes." (P6) }\end{array}$} \\
\hline
\end{tabular}

Figure 5. Post-project (consideration) survey results and comments. 
noted that they would consider using such a system as teachers $(M=3.86$; Figure 5). However, it should be noted that most post-project survey comments/evaluations were not related to the scheduling and task interleaving of ISRS but the integration or lack of other external features (see Figures 6 and 7).

In terms of usability (see Figure 8), there were some concerns about the digital fluency level of potential users, especially younger students and older teachers. Also, the potential lack of in-class/in-school digital facilities and resources were also a point of contention (e.g., lack of [tablet] computers and/or lack of Wi-Fi connectivity). Finally, although few, there were also some apprehensions about assigning online review as homework because of differences in students' access to reliable internet.

In terms of enjoyment (see Figure 7), two important areas for improvement were identified: first, the need for more detailed progress boards (individual

\begin{tabular}{|c|c|c|}
\hline Perceptions (5 point Likert-scale, 5 = strongly agree) and Comments (P\# = Participant \#) & Mean & $S D$ \\
\hline (Usefulness) I think that this software is an effective tool for JHS students learning English. & 3.71 & 0.76 \\
\hline \multicolumn{3}{|c|}{$\begin{array}{l}\text { "It's good for students because the words they must memorize or recall are suggested automatically. So, } \\
\text { I think it's effective." (P1) }\end{array}$} \\
\hline \multicolumn{3}{|c|}{$\begin{array}{l}\text { "At the JHS level, I believe that students who have difficulty with English also have a general difficulty with } \\
\text { memorization. With the use of such a tool, students can become more familiar with the concept of memory and } \\
\text { increase it. Moreover, as the software asks users to type the words frequently, memorization becomes easy." (P2) }\end{array}$} \\
\hline \multicolumn{3}{|c|}{$\begin{array}{l}\text { "The loaded content (questions/tasks) might be too easy for some students, so if the users could choose the } \\
\text { difficulty level it would make the software better." (P4) }\end{array}$} \\
\hline \multicolumn{3}{|c|}{$\begin{array}{l}\text { "I think that this software is a very effective tool for learning English because it utilizes a quiz style approach. Also } \\
\text { when answers are checked we can listen to the pronunciation." (P5) }\end{array}$} \\
\hline \multicolumn{3}{|c|}{$\begin{array}{l}\text { "I think this software would be better if it provided the users with more detailed records of their progress and a } \\
\text { daily performance report; this could be used as a reminder to login. Also, some sentences took some time to } \\
\text { be loaded (lag)." (P6) }\end{array}$} \\
\hline
\end{tabular}

Figure 6. Post-project (usefulness) survey results and comments.

\begin{tabular}{|c|c|c|}
\hline Perceptions ( 5 point Likert-scale, 5 = strongly agree) and Comments ( $\mathrm{P \#} \mathrm{=} \mathrm{Participant} \mathrm{\# )}$ & Mean & $S D$ \\
\hline (Enjoyment) I think that JHS students would enjoy using such software as part of their study. & 3.57 & 0.98 \\
\hline \multicolumn{3}{|l|}{$\begin{array}{l}\text { "As users progress through the software, I think that they need to have a better sense of their progress. } \\
\text { For example, just as in a game, the screen could change and show their level going up." (P2) }\end{array}$} \\
\hline \multicolumn{3}{|c|}{$\begin{array}{l}\text { "Students are used to writing on paper or listening to CDs, so using software with their PC or phone would be fun and } \\
\text { interesting to them." (P4) }\end{array}$} \\
\hline \multicolumn{3}{|c|}{$\begin{array}{l}\text { "Incorporating native English voices is a great point and they can feel the passion (of the characters/voice actors). } \\
\text { The change in colors of buttons when running out of time was a nice touch too." (P6) }\end{array}$} \\
\hline \multicolumn{3}{|c|}{$\begin{array}{l}\text { "The software could be more convincing with illustrations/animations of words, as just writing "good" or "wrong" in } \\
\text { plain text seemed a bit regrettable." (P6) }\end{array}$} \\
\hline
\end{tabular}

Figure 7. Post-project (enjoyment) survey results and comments. 


\begin{tabular}{|c|c|c|}
\hline Perceptions ( 5 point Likert-scale, 5 = strongly agree) and Comments ( $\mathrm{P \#} \mathrm{=} \mathrm{Participant} \mathrm{\# )}$ & Mean & $S D$ \\
\hline (Usefulness) I think that this software is an effective tool for JHS students learning English. & 3.43 & 0.98 \\
\hline \multicolumn{3}{|c|}{$\begin{array}{l}\text { "The font on the cellphone version is hard to read, even more so for JHS students. Moreover, the software doesn't } \\
\text { include enough explanations in terms of how-to use it." (P3) }\end{array}$} \\
\hline \multicolumn{3}{|c|}{$\begin{array}{l}\text { "For people who are not accustomed to using computers or smartphones, using this software may prove a little } \\
\text { difficult. But most students will be able to easily use it without any trouble." (P4) }\end{array}$} \\
\hline
\end{tabular}

Figure 8. Post-project (usability) survey results and comments.

progress bar and leaderboards) and, second, the need for further gamification, such as an in-game reward system linked to achievement, but perhaps more importantly to consistency in participation. For increased efficiency, such progress and rewards should be linked to students' overall participation scores.

\section{Conclusion}

The main goal of this research was to systemize, build, and test prototype software to demonstrate ISRS as a viable concept. This was achieved; however, the conducted survey revealed some areas that could be further improved as discussed above. To use the analogy of high cuisine where plating or presentation is as important as taste, in today's context of e-learning, gamification features are just as important as the core structure of learning itself.

This is a testament to the importance of gamification for users, which has become a research area of interest for the author. A second area of importance is further research in spacing algorithms, especially comparing expanded types of algorithms $\left(+, \times\right.$, and $\left.\mathrm{a}^{\mathrm{b}}\right)$ among themselves. A third area of importance is building various word lists appropriate for different levels of learners.

Some of the author's current projects on a similar line of investigation include research on teachers' perspectives on word counting units, creating common core elementary/junior high level word lists, and testing and supplementing the New Academic Word List (NAWL; Browne, Culligan, \& Phillips, 2013) with example sentences and translations (Kanazawa \& Lafleur, 2019).

\section{Acknowledgments}

The author is grateful to his former professors at Okayama University who supported this research in its early phases, to the staff at MageMontreal for their help in web application programing, and, finally, to the reviewer and journal editor for their advice and assistance.

\section{Author's contribution section}

The empirical participant data used in this article are taken from the author's 2015 master thesis study. Otherwise, other sections including changes made to the publicly available ISRS concept are unique to this article. 


\section{References}

Balota, D. A., Duchek, J. M., \& Logan, J. M. (2007). Is expanded retrieval practice a superior form of spaced retrieval? A critical review of the extant literature. In J. S. Nairne (Ed.), The foundations of remembering: Essays in honor of Henry L. Roediger III (pp. 83-105). New York, NY: Psychology Press.

Browne, C., Culligan, B., \& Phillips, J. (2013). New Academic Word List (NAWL). Licensed under a Creative Commons Attribution-ShareAlike 4.0 International License. Retrieved from http://www.newgeneralservicelist.org/ nawl-new-academic-word-list

Carpenter, S. K., \& DeLosh, E. L. (2005). Application of the testing and spacing effects to name learning. Applied Cognitive Psychology, 19, 619-636. doi:10.1002/acp.1101

Ebbinghaus, H. (1964). Über das gedächtnis: Untersuchungen zur experimentellen psychologie [Memory: A Contribution to Experimental Psychology]. Gloucester, MA: Smith; New York: Dover. (Original work published 1885)

Kanazawa, Y., \& Lafleur, L. (2019). E-NAWL: Building of an enlarged, emotional, electronic NAWL. Paper presented at the 52nd annual meeting of the British Association of Applied Linguistics (BAAL2019), Manchester Metropolitan University, Manchester, England. (August 29th, 2019)

Lafleur, L. (2015). The conceptualization of balanced and multifaceted vocabulary learning systems (M.A.). Okayama University, Okayama, Japan. Available on researchgate.net. doi:10.13140/RG.2.2.22161.84327/1

Landauer, T. K., \& Bjork, R. A. (1978). Optimum rehearsal patterns and name learning. In M. Gruneberg, P. E. Morris, \& R. N. Sykes (Eds.), Practical aspects of memory (pp. 625-632). London, UK: Academic Press.

Leitner, S. (1972). So lernt man lernen: Der weg zum erfolg [How to learn to learn: The road to success]. Freiburg im Breisgau, Baden-Württemberg: Verlag Herder.

Nation, I. S. P. (2001). Learning vocabulary in another language. Cambridge: Cambridge University Press.

Pimsleur, P. (1967). A memory schedule. Modern Language Journal, 51, 73-75. doi:10.1111/j.1540-4781.1967.tb06700.x

Schmitt, N. (2008). Instructed second language vocabulary learning. Language Teaching Research, 12(3), 329-363. doi:10.1177/1362168808089921

Schuetze, U., \& Weimer-Stuckmann, G. (2010). Virtual vocabulary: Research and learning in lexical processing. CALICO Journal, 27, 517-528. doi:10.11139/ cj.27.3.517-528

Schuetze, U., \& Weimer-Stuckmann, G. (2011). Retention in SLA lexical processing. CALICO Journal, 28, 460-472. doi:10.11139/cj.28.2.460-472 